\title{
Características morfogênicas e estruturais do capim-andropogon sob irrigação e adubação
}

\section{Morphogenetic and structural characteristics of andropogon grass under irrigation and fertilization}

\author{
João Avelar Magalhães ${ }^{*}$; Maria Socorro de Souza Carneiro²; \\ Alex Carvalho Andrade ${ }^{3}$; Elzânia Sales Pereira'; Alberício Pereira de Andrade ${ }^{5}$; \\ Olaf Andreas Bakke ${ }^{6}$; Braz Henrique Nunes Rodrigues ${ }^{7}$; \\ William de Jesus Ericeira Mochel Filho ${ }^{8}$; Newton de Lucena Costa ${ }^{9}$
}

\section{Resumo}

Avaliou-se os efeitos de diferentes lâminas de irrigação e doses de nitrogênio (N) sobre as características morfogênicas e estruturais do capim-andropogon (Andropogon gayanus cv. Planaltina). O estudo foi conduzido no período de agosto a dezembro de 2007, na área experimental da EMBRAPA Meio-Norte, em Parnaíba, Piauí. Os tratamentos consistiram em duas lâminas de irrigação (equivalentes à reposição de $50 \%$ e $80 \%$ da Evaporação do Tanque Classe A - ECA) e quatro doses de nitrogênio (equivalente a $200,400,600$ e $800 \mathrm{~kg}$ de N/ha/ano), em delineamento em blocos casualizados, e esquema fatorial $2 \times 4$, com três repetições. A adubação nitrogenada, sob forma de uréia, foi aplicada de acordo com as quantidades estabelecidas nos tratamentos $(16,7 ; 33,3 ; 50,0$ e $66,7 \mathrm{~kg}$ de $\mathrm{N} /$ corte). A redução da lâmina de irrigação proporcionou decréscimos nas taxas de alongamento da folha, aparecimento de folha, comprimento final da folha e número de folhas vivas, enquanto a taxa de senescência aumentou. A adubação incrementou as taxas de alongamento da folha, aparecimento de folha e comprimento final da folha. No entanto, tendeu a reduzir o número de folhas vivas e a ampliar a taxa de senescência.

Palavras-chave: Andropogon gayanus, irrigação de pastagem, nitrogênio

\begin{abstract}
It was evaluated the effects of different irrigation and nitrogen $(\mathrm{N})$ doses on morphogenesis and structural Andropogon grass (Andropogon gayanus cv. Planaltina). The study was conducted in period from August to December, 2007 in experimental area of EMBRAPA Meio-Norte, located in city of Parnaíba, Piauí, Brazil. The treatments consisted of two irrigation levels (equivalent to replacement of
\end{abstract}

\footnotetext{
${ }^{1}$ Médico Veterinário, D.Sc., Pesquisador da Empresa Brasileira de Pesquisa Agropecuária/Centro de Pesquisa Agropecuária do Meio-Norte, EMBRAPA, Parnaíba, PI. E-mail: joao.magalhaes@embrapa.br

${ }^{2}$ Eng $^{\circ}$ Agr $^{\circ}$, D.Sc., Prof ${ }^{a}$ da Universidade Federal do Ceará, UFC, Fortaleza, CE. E-mail. msocorro@ufc.br

${ }^{3}$ Zootecnista, D.Sc., Prof. da Universidade Estadual do Piauí, UESPI, Parnaíba, PI. E-mail: acandrade4@hotmail.com

${ }^{4}$ Zootecnista, D.Sc., Prof ${ }^{a}$ da UFC, Fortaleza, CE. E-mail: elzania@hotmail.com

${ }^{5}$ Eng $^{\mathrm{o}}$ Agr ${ }^{\circ}$, D.Sc., Prof. da Universidade Federal da Paraíba, UFPB, Areia, PB. E-mail: albericio@cca.ufpb.br

${ }^{6}$ Eng $^{\text {o }}$ Agr $^{\circ}$, D.Sc., Prof. da Universidade Federal de Campina Grande, UGCG, Patos, PB. E-mail: obakke@cstr.ufcg.edu.br

${ }^{7}$ Engenheiro Agrícola, D.Sc., Pesquisador da Empresa Brasileira de Pesquisa Agropecuária/Centro de Pesquisa Agropecuária do

Meio-Norte, EMBRAPA, Parnaíba, PI. E-mail: braz.rodrigues@embrapa.br

${ }^{8}$ Eng $^{\circ}$ Agr $^{\circ}$, M.Sc., Discente do Curso de Doutorado em Zootecnia, UFC, Fortaleza, CE. E-mail: william.mochel@gmail.com

${ }^{9}$ Eng $^{\mathrm{o}} \mathrm{Agr}^{\circ}$, D.Sc., Pesquisador da EMBRAPA, Centro de Pesquisa Agroflorestal de Roraima, Boa Vista, RO. E-mail: newton.lucenacosta@embrapa.br

* Autor para correspondência
} 
$50 \%$ and $80 \%$ of the Class A pan evaporation - ECA) and four doses of nitrogen (equivalent to 200, 400,600 and $800 \mathrm{~kg} \mathrm{~N} / \mathrm{ha} /$ year) in a randomized block design in factorial $2 \times 4$ with three replications. The nitrogen in the form of urea was applied according to the amounts specified in the treatments (16.7, $33.3,50.0$ and $66.7 \mathrm{~kg} \mathrm{~N} / \mathrm{cut}$ ). The reduction in water depth provided decreases in leaf elongation rate, leaf appearance, final leaf length and number of life leaves, while the rate of senescence increases. Fertilization increased the leaf elongation rate and leaf appearance. However, tended to reduce the number of life of leaves and expand the level senescence.

Key words: Andropogon gayanus, nitrogen, pasture irrigation

\section{Introdução}

Morfogênese pode ser definida como a dinâmica de geração e expansão da forma da planta no espaço. O surgimento, a expansão, a senescência e a morte das folhas, definem o fluxo de biomassa do relvado e determinam o índice de área foliar. Nas gramíneas em crescimento vegetativo, a morfogênese pode ser descrita por três características básicas: taxa de aparecimento de folhas, taxa de alongamento e a taxa de senescência da folha. Estas características, embora programadas geneticamente, são influenciadas pela temperatura ambiente, disponibilidade hídrica e de nutrientes no solo. A combinação das variáveis morfogênicas com os fatores ambientais determina a dinâmica do fluxo de tecidos e as características estruturais das pastagens: tamanho da folha, densidade de perfilhos e número de folhas por perfilho (PARSONS; PENNING, 1988; CHAPMAN; LEMAIRE, 1993).

De outro lado, para reduzir a estacionalidade da produção de forragens se torna indispensável a utilização de tecnologias como irrigação de pastagens, para possibilitar aumentos nas características de crescimento e de produção da planta forrageira. Segundo Dias Filho, Corsi e Cusato (1989), a disponibilidade de água afeta a produção de biomassa das gramíneas, e períodos de déficit hídrico podem ser considerados os maiores limitantes climáticos para o desenvolvimento de forrageiras em ambiente tropical. Para Santos e Carlesso (1998) a diminuição do conteúdo de água no solo afeta acentuadamente os processos morfofisiológicos das plantas.

Além disso, a produção forrageira, como resultado dos processos de crescimento e desenvolvimento, pode ter sua eficiência substancialmente melhorada pelo aumento do uso de fertilizantes, principalmente pela ação do nitrogênio, por meio da sua expressiva influência no fluxo de biomassa (DURU; DUCROCQ, 2000a). Costa, Paulino e Magalhães (2006) verificaram efeitos positivos do nitrogênio sobre as características morfogênicas e estruturais do capim Panicum maximum cv. Vencedor.

Portanto, o sucesso na utilização de pastagens também depende, além da espécie forrageira, da disponibilidade hídrica e de nutrientes, do entendimento dos mecanismos morfofisiológicos e da sua interação com o ambiente, ponto fundamental para suportar tanto o crescimento quanto a manutenção da capacidade produtiva da pastagem e reduzir as perdas por senescência (GARCEZ NETO et al., 2002).

Esse experimento teve como objetivo avaliar os efeitos de diferentes lâminas de água de irrigação e da adubação nitrogenada sobre as características morfogênicas e estruturais do capim Andropogon gayanus cv. Planaltina.

\section{Material e Métodos}

O trabalho foi realizado na Embrapa Meio-Norte, em Parnaíba, Piauí, durante o período de agosto a dezembro de 2007. O clima é do tipo Aw', segundo classificação de Köppen, com vento moderado e umidade relativa do ar de moderada a alta. A precipitação anual média é de $1.300 \mathrm{~mm}$ e o período chuvoso se concentra nos meses de janeiro a junho. O solo do local foi classificado como Latossolo Amarelo distrófico, com as seguintes características principais: solo profundo, acentuadamente drenado, 
de textura variando de média a argilosa no horizonte $\mathrm{B}$, densidade do solo relativamente alta $(1,3$ a $1,6 \mathrm{~kg}$ $\mathrm{m}^{3}$ ) com valores médios de $846 \mathrm{~g} / \mathrm{kg}$ de areia, $58 \mathrm{~g} /$ $\mathrm{kg}$ de silte e $95 \mathrm{~g} / \mathrm{kg}$ de argila. (MELO et al., 2004). No início do experimento apresentou as seguintes características químicas: $\mathrm{MO}=15,28 \mathrm{~g} / \mathrm{kg} ; \mathrm{pH}$ $\left(\mathrm{H}_{2} \mathrm{O}\right)=5,48 ; \mathrm{P}=13,45 \mathrm{mg} / \mathrm{dm}^{3} ; \mathrm{K}=0,04 \mathrm{cmol}_{\mathrm{c}}$ / $\mathrm{dm}^{3} ; \mathrm{Ca}=1,51 \mathrm{cmol}_{\mathrm{c}} / \mathrm{dm}^{3} ; \mathrm{Mg}=0,44 \mathrm{cmol}_{\mathrm{c}} / \mathrm{dm}^{3}$; $\mathrm{Na}=0,16 \mathrm{cmol}_{\mathrm{c}} / \mathrm{dm}^{3} ; \mathrm{Al}=0,01 \mathrm{cmol}_{\mathrm{c}} / \mathrm{dm}^{3} ; \mathrm{H}+\mathrm{Al}$ $=1,25 \mathrm{cmol}_{\mathrm{c}} / \mathrm{dm}^{3} ; \mathrm{S}=2,14 \mathrm{cmol}_{\mathrm{c}} / \mathrm{dm}^{3} ; \mathrm{CTC}=3,40$ $\mathrm{cmol}_{\mathrm{c}} / \mathrm{dm}^{3} ; \mathrm{V}=63,04 \% ; \mathrm{m}=0,69 \%$.

As parcelas experimentais foram implantadas no início do período chuvoso de 2005, aplicandose, em fundação, em todas as parcelas, a dosagem equivalente a $50 \mathrm{~kg} / \mathrm{ha}$ de $\mathrm{P}_{2} \mathrm{O}_{5}$, na forma de superfosfato triplo e $40 \mathrm{~kg} / \mathrm{ha}$ de $\mathrm{K}_{2} \mathrm{O}$, na forma de cloreto de potássio, além de $45 \mathrm{~kg} / \mathrm{ha}$ de nitrogênio na forma de uréia, parceladas em duas aplicações, uma no plantio e outra 30 dias após.

Os tratamentos consistiram em duas lâminas de irrigação (estimativas da reposição de $50 \%$ e $80 \%$ da Evaporação do Tanque Classe A - ECA) e quatro doses de nitrogênio (estimativas de 200, 400, 600 e $800 \mathrm{~kg}$ de N/ha/ano), em delineamento em blocos casualizados, e esquema fatorial $2 \times 4$, com três repetições. As parcelas experimentais mediam $3 \mathrm{~m}$ x $8 \mathrm{~m}$, sendo realizados um corte de uniformização (agosto) e quatro cortes para coleta de dados a cada 30 dias (setembro, outubro, novembro, dezembro), a $20 \mathrm{~cm}$ do solo.

A adubação nitrogenada, sob forma de uréia, foi aplicada a lanço e de acordo com as quantidades estabelecidas nos tratamentos $(16,7 ; 33,3 ; 50,0$ e $66,7 \mathrm{~kg}$ de N/corte). Durante o período experimental foram aplicados 66,8; 133,2; 200,00 e 266,8 $\mathrm{kg}$ de $\mathrm{N} /$ ha, respectivamente.

$\mathrm{Na}$ irrigação foi utilizado um sistema de aspersão convencional fixo, de baixa pressão e vazão, utilizando-se um turno de rega de três dias, cujo espaçamento entre linhas laterais e entre aspersores foi de $12 \mathrm{~m}$ x $12 \mathrm{~m}$. Durante o período experimental, os valores das lâminas totais de irrigação aplicadas nos tratamentos dos níveis de irrigação foram de 471,99 mm (50\% de ECA) e $755,18 \mathrm{~mm}$ ( $80 \%$ de ECA).

Para coleta dos dados de morfogênese, foram marcados com cordas de nylon coloridas dois perfilhos basilares por parcela, e com o uso de uma régua, foram realizadas medições, duas vezes por semana, anotando-se os valores em planilhas previamente elaboradas. A lâmina foliar foi medida até sua completa expansão, ou seja, até o aparecimento da lígula. O comprimento da lâmina emergente foi medido do seu ápice até a lígula da última folha expandida, ou até sua completa expansão. A senescência foi identificada pelo amarelecimento do ápice laminar, onde foram consideradas como folha senescente (morta) aquelas que apresentaram mais que $50 \%$ de sua lâmina amarelecida. Com os dados registrados nas planilhas, foram calculadas as seguintes variáveis: Taxa de Alongamento de Folhas (TAlF - cm/perfilho/dia) - foi obtida subtraindo-se o comprimento total inicial de lâminas foliares do comprimento total final e dividindo-se a diferença pelo número de dias envolvidos; Taxa de Aparecimento de Folhas (TApF - folhas/perfilho/ dia) - foi obtida pela divisão do número de folhas completamente expandidas (lígula exposta) surgidas por perfilho pelo número de dias envolvidos; Taxa de Senescência de Folhas (TSF - cm/perfilho/dia) - foi calculada dividindo-se o comprimento final total do tecido senescente, pelo número de dias envolvidos; Comprimento Final da Lâmina Foliar (CFLF - cm): foram medidas as folhas completamente expandidas, desde sua inserção na lígula até o ápice foliar. Número de Folhas Vivas por perfilho (NFV - unidade) - foi determinado o número de folhas emergentes e expandidas do perfilho, desconsiderando-se as que apresentavam mais de 50\% de senescência.

\section{Resultados e Discussão}

A Taxa de Alongamento de Folhas (TAlF) do capim-andropogon foi influenciada $(\mathrm{P}<0,01)$ pelas lâminas de irrigação (Tabela 1). A aplicação 
da menor lâmina de irrigação resultou em decréscimo de 34,15\% na Taxa de Alongamento de Folhas, demonstrando que plantas respondem morfologicamente e fisiologicamente a escassez de água, de forma a reduzir a perda de água. O alongamento da folha é um dos processos fisiológicos mais sensíveis à umidade do solo, pois a planta cessa o crescimento de folhas e raízes muito antes que os processos de fotossíntese e divisão celular sejam afetados (LUDLOW; NG, 1977).

A redução da Taxa de Alongamento de Folhas observada neste experimento está de acordo com Mochel Filho (2009) que obteve Taxa de Alongamento de Folhas de 2,21 e 1,50 cm/perfilho/ dia em capim-Mombaça (Panicum maximum cv. Mombaça), submetido às lâminas de $80 \%$ e $50 \%$ de ECA, respectivamente. No entanto, Alves et al. (2008), trabalhando em casa de vegetação, não evidenciaram alterações significativas na Taxa de
Alongamento de Folhas em Brachiaria decumbens, quando aumentaram a disponibilidade de água no solo de $40 \%$ para $80 \%$ da capacidade de campo.

A adubação nitrogenada promoveu efeito quadrático na Taxa de Alongamento de Folhas (Tabela 1), sendo o máximo valor estimado em 3,24 $\mathrm{cm} /$ perfilho/dia, obtido com a aplicação de $51,3 \mathrm{~kg}$ de N/ha/corte, ou seja, 615,6 kg de N/ha/ano, fato observado apenas na lâmina de $80 \%$, evidenciando assim, que doses crescentes de nitrogênio aumentam, até certo ponto, a taxa de alongamento de folhas. $\mathrm{O}$ efeito do nitrogênio sobre a taxa de alongamento foliar decorre do maior acúmulo desse nutriente na zona de alongamento da folha, mais especificamente na região de divisão celular (GASTAL; NELSON, 1994). Duru e Ducrocq (2000b) também observaram aumento de 80\% na Taxa de Alongamento de Folhas em Dactylis glomerata com aplicação de $120 \mathrm{~kg}$ de N/ha.

Tabela 1. Taxa de alongamento de folhas (TAlF) do capim Andropogon gayanus cv. Planaltina, sob irrigação e adubação nitrogenada (N) em Parnaíba, Piauí.

\begin{tabular}{|c|c|c|c|c|c|c|}
\hline \multirow{3}{*}{$\begin{array}{l}\text { Lâminas de } \\
\text { irrigação }\end{array}$} & \multicolumn{4}{|c|}{ Doses de N (kg/ha/ano) } & \multirow{3}{*}{ Médias** } & \multirow{3}{*}{ Equação de regressão } \\
\hline & 200 & 400 & 600 & 800 & & \\
\hline & \multicolumn{4}{|c|}{ TAlF (cm/perfilho/dia) } & & \\
\hline $50 \%$ de ECA & 1,87 & 1,80 & 2,06 & 1,76 & $1,87^{\mathrm{B}}$ & Sem ajuste \\
\hline $80 \%$ de ECA & 2,14 & 2,99 & 3,21 & 3,04 & $2,84^{\mathrm{A}}$ & $\begin{array}{c}\hat{y}=0,862179+0,093128 \mathrm{~N}- \\
0,000908 * \mathrm{~N}^{2} ; \mathrm{R}^{2}=0,99\end{array}$ \\
\hline
\end{tabular}

** Na coluna, médias seguidas por letras distintas diferem entre si, pelo teste de Tukey a 1\%.

* Significativo a 5\% de probabilidade. ECA = Evaporação do Tanque Classe A.

Fonte: Elaboração dos autores.

A Taxa de Aparecimento de Folhas (TApF) foi influenciada pela interação nitrogênio x lâminas de irrigação $(\mathrm{P}<0,01)$ (Tabela 2). Em todas as doses de nitrogênio, exceto na menor, observou-se maior Taxa de Aparecimento de Folhas na maior lâmina de irrigação. Geralmente, a luz e a temperatura são os fatores que mais afetam a Taxa de Aparecimento de Folhas, mas também esta variável pode receber influência da disponibilidade hídrica do solo e da adubação nitrogenada (ZANINE; SANTOS; FERREIRA, 2007). Aumento de $25 \%$ na Taxa de Aparecimento de Folhas do capim B. decumbens foi obtido por Alves et al. (2008) quando duplicaram a disponibilidade de água no solo. No mesmo experimento não foi observado efeito da adubação nitrogenada. 
Tabela 2. Taxa de aparecimento de folhas (TApF) do capim Andropogon gayanus cv. Planaltina, sob irrigação e adubação nitrogenada (N) em Parnaíba, Piauí.

\begin{tabular}{|c|c|c|c|c|c|c|}
\hline \multirow{3}{*}{$\begin{array}{l}\text { Lâminas de } \\
\text { irrigação }\end{array}$} & \multicolumn{4}{|c|}{ Doses de N (kg/ha/ano) } & \multirow{3}{*}{ Médias $^{* *}$} & \multirow{3}{*}{ Equação de regressão } \\
\hline & 200 & 400 & 600 & 800 & & \\
\hline & \multicolumn{4}{|c|}{ TApF/perfilho/dia } & & \\
\hline $50 \%$ de ECA & $0,162^{\text {Aa }}$ & $0,143 \mathrm{Ba}$ & $0,146^{\mathrm{Ba}}$ & $0,143^{\mathrm{Ba}}$ & $0,148^{\text {в }}$ & Sem ajuste \\
\hline $80 \%$ de ECA & $0,160^{\mathrm{Ab}}$ & 0,182 Aab & 0,201 Aab & $0,209^{\text {Aa }}$ & $0,188^{\mathrm{A}}$ & $\begin{array}{c}\hat{\mathrm{y}}=0,1466+0,001002 * \mathrm{~N} \\
\mathrm{R}^{2}=0,95\end{array}$ \\
\hline
\end{tabular}

** Médias seguidas de mesma letra não diferem entre si pelo teste Tukey a 1\%, respectivamente, minúsculas nas linhas e maiúsculas nas colunas.

* Significativo a 5\% de probabilidade. ECA = Evaporação do Tanque Classe A

Fonte: Elaboração dos autores.

A análise de regressão revelou efeito linear positivo da adubação nitrogenada sobre a Taxa de Aparecimento de Folhas do capim-andropogon, fato registrado apenas na maior lâmina aplicada (Tabela 2). Em pesquisa conduzida com capim-Mombaça, em casa de vegetação, Garcez Neto et al. (2002) revelaram que o maior nível de adubação aumentou em 104\% a Taxa de Aparecimento de Folhas em relação à testemunha. No entanto, Pinto, Gomide e Maestri (1994), em estudo com capim-guiné ( $P$. maximum) e capim-setária (Setaria anceps Stapf.), não observaram influência do nitrogênio na Taxa de
Aparecimento de Folhas.

A menor lâmina de irrigação causou redução $(\mathrm{P}<0,01)$ de 25,02\% no Comprimento Final da Lâmina Foliar (CFLF) do capim-andropogon (Tabela 3), em relação à maior lâmina de irrigação, provavelmente, devido a diminuição do alongamento foliar. Em pesquisa com capimelefante (Pennisetum purpureum), Barreto et al. (2001) observaram uma redução de 28,46\% no comprimento da lâmina foliar, passando de 69,9 $\mathrm{cm}$, nas parcelas irrigadas para $50 \mathrm{~cm}$ naquelas submetidas ao estresse hídrico.

Tabela 3. Comprimento final da lâmina foliar (CFLF) do capim Andropogon gayanus cv. Planaltina, sob irrigação e adubação nitrogenada (N) em Parnaíba, Piauí.

\begin{tabular}{|c|c|c|c|c|c|c|}
\hline \multirow{3}{*}{$\begin{array}{l}\text { Lâminas de } \\
\text { irrigação }\end{array}$} & \multicolumn{4}{|c|}{ Doses de N (kg/ha/ano) } & \multirow{3}{*}{ Médias** } & \multirow{3}{*}{ Equação de regressão } \\
\hline & 200 & 400 & 600 & 800 & & \\
\hline & \multicolumn{4}{|c|}{ CFLF (cm) } & & \\
\hline $50 \%$ de ECA & 20,60 & 21,76 & 22,09 & 21,11 & $21,39^{\mathrm{B}}$ & Sem ajuste \\
\hline $80 \%$ de ECA & 25,71 & 29,13 & 30,35 & 28,53 & $28,43^{\mathrm{A}}$ & $\begin{array}{c}\hat{\mathrm{y}}=19,442+0,449 \mathrm{~N}-0,00461 * \mathrm{~N}^{2} ; \mathrm{R}^{2} \\
=0,99\end{array}$ \\
\hline
\end{tabular}

** Na coluna, médias seguidas por letras distintas diferem entre si, pelo teste de Tukey a $1 \%$ de probabilidade. * Significativo a 5\% de probabilidade. ECA = Evaporação do Tanque Classe A

Fonte: Elaboração dos autores.

A adubação nitrogenada, na maior lâmina de irrigação, promoveu efeito quadrático no Comprimento Final da Lâmina Foliar (Tab. 3), sendo o máximo valor estimado em $30,36 \mathrm{~cm}$ e obtido com a aplicação de 48,6 kg de N/ha/corte, ou seja, 583,2 kg de N/ha/ano, indicando que a adubação nitrogenada promove o crescimento de forma linear até certo ponto. Tendências semelhantes foram observadas 
por Mesquita e Neres (2008), após adubarem várias cultivares de $P$. maximum, com níveis de 0 a $400 \mathrm{~kg}$ de N/ha; Costa, Paulino e Magalhães (2006), em $P$. maximum cv. Vencedor, sob níveis de até $320 \mathrm{~kg}$ de $\mathrm{N} / \mathrm{ha}$, em Latossolo Amarelo, textura argilosa, em casa de vegetação.

Conforme Skinner e Nelson (1995), o comprimento final da lâmina foliar e bainha aumentam em sucessivas folhas de um perfilho até se manter constante, padrão revertido quando os entrenós se alongam, de modo que a folha fica menor em relação à bainha e, portanto, a folha bandeira é mais curta do que as folhas basais do perfilho. Diferenças no comprimento final das folhas também podem ser atribuídas aos valores de Taxa de Aparecimento de Folhas, pois, quanto maiores esses valores, maior será a tendência de produção de folhas curtas por perfilho (BARBOSA et al., 2002).

Segundo Garcez Neto et al. (2002), quando as condições para o crescimento são favoráveis e constantes, a divisão celular é também favorecida, tornando possível obter lâminas maiores para mesmo comprimento de bainha. De acordo com esses autores, o aumento no tamanho de lâmina pode ser explicado pelo efeito simultâneo do nitrogênio, que aumenta de forma expressiva o número de células em processo de divisão. O nitrogênio ao estimular a produção de novas células, possibilita aumento na taxa de alongamento das folhas, o que pode constituir uma estratégia da planta para mudanças no tamanho da lâmina foliar.

Embora a menor lâmina de água tenha aumentado em 11,26\% a Taxa de Senescência de Folhas (TSF) do capim-andropogon, este incremento não foi significativo $(\mathrm{P}>0,05)$ (Tab. 4). A tolerância do capim-andropogon à escassez de água no solo é uma das peculiaridades desta gramínea. Observações semelhantes foram relatadas por Wilson e Mannetje (1978), ao estudarem o capim-buffel (Cenchrus ciliaris) e o capim Green-Panic (P. maximum) em condições de estresse hídrico. Conforme Wright, Smith e Mcwilliam (1983), a baixa umidade no solo aumenta a senescência de folhas, porque nestas condições ocorre redução da absorção de nutrientes pelas plantas, dentre eles o nitrogênio, fazendo com que este nutriente seja translocado das folhas mais velhas para os pontos de crescimento. A senescência foliar reduz a quantidade de forragem de qualidade, pois as porções verdes da planta são as mais nutritivas para a dieta animal.

Dentro da maior lâmina de irrigação foi observado efeito quadrático (Tabela 4), sendo a máxima Taxa de Senescência de Folhas (TSF) estimada em 1,49 cm/perfilho/dia, obtida com a aplicação de 44,1 $\mathrm{kg}$ de N/ha/corte, ou seja, 529,2 kg de N/ha/ano. É possível que a maior dosagem aplicada, combinada com o tipo de solo do local onde foi realizado este trabalho, tenha contribuído para limitar a influência do nitrogênio na Taxa de Senescência de Folhas, que pode ter sofrido perdas por lixiviação. Pompeu et al. (2010) também reportaram efeito quadrático dos níveis de adubação nitrogenada sobre a Taxa de Senescência de Folhas do capimaruana (P. maximum), após estudar as características morfogênicas desta gramínea em casa-de-vegetação.

Tabela 4. Taxa de senescência de folhas (TSF) do capim Andropogon gayanus cv. Planaltina, sob irrigação e adubação nitrogenada (N) em Parnaíba, Piauí.

\begin{tabular}{|c|c|c|c|c|c|c|}
\hline \multirow{3}{*}{$\begin{array}{l}\text { Lâminas de } \\
\text { irrigação }\end{array}$} & \multicolumn{4}{|c|}{ Doses de N (kg/ha/ano) } & \multirow{3}{*}{ Médias } & \multirow{3}{*}{ Equação de regressão } \\
\hline & 200 & 400 & 600 & 800 & & \\
\hline & \multicolumn{4}{|c|}{ TSF (cm/perfilho/dia) } & & \\
\hline $50 \%$ de ECA & 1,47 & 1,50 & 1,51 & 1,21 & 1,42 & Sem ajuste \\
\hline $80 \%$ de ECA & 1,09 & 1,11 & 1,77 & 1,05 & 1,26 & $\begin{array}{c}\hat{\mathrm{y}}=0,20818+0,058384 \mathrm{~N}-0,000662 * \mathrm{~N}^{2} ; \mathrm{R}^{2} \\
=0,42\end{array}$ \\
\hline
\end{tabular}

* Significativo a 5\% de probabilidade. ECA = Evaporação do Tanque Classe A

Fonte: Elaboração dos autores. 
O Número de Folhas Vivas por perfilho (NFV/ perfilho) foi influenciado $(\mathrm{P}<0,05)$ pelas lâminas de irrigação, cuja maior média (4,73 FV/perfilho) foi registrada com a aplicação da lâmina de $80 \%$ de ECA, superando em 9,94\% a média da menor lâmina de irrigação (Tabela 5). O Número de Folhas Vivas por perfilho por ser definido geneticamente e é praticamente inalterado na ausência de deficiências hídricas e nutricionais (NABINGER; PONTES, 2001). Em plantas forrageiras, segundo
Rodrigues, Rodrigues e Reis (1993), a baixa disponibilidade de água no solo pode limitar a taxa de alongamento foliar, o número de folhas vivas e o número de perfilhos. Em B. decumbens, Alves et al. (2008) observaram diminuição de 4,7 FV/ perfilho para 3,8 $\mathrm{FV} /$ perfilho quando reduziram de $80 \%$ para $40 \%$ o volume de água aplicada de acordo com a capacidade campo, representando um decréscimo de 19,14\% no Número de Folhas Vivas por perfilho.

Tabela 5. Número de folhas vivas/perfilho (NFV/perfilho) do capim Andropogon gayanus cv. Planaltina, sob irrigação e adubação nitrogenada (N) em Parnaíba, Piauí.

\begin{tabular}{|c|c|c|c|c|c|c|}
\hline \multirow{3}{*}{$\begin{array}{l}\text { Lâminas de } \\
\text { irrigação }\end{array}$} & \multicolumn{4}{|c|}{ Doses de N (kg/ha/ano) } & \multirow{3}{*}{ Médias* } & \multirow{3}{*}{ Equação de regressão } \\
\hline & 200 & 400 & 600 & 800 & & \\
\hline & \multicolumn{4}{|c|}{ NFV/perfilho } & & \\
\hline $50 \%$ de ECA & 4,62 & 4,50 & 3,87 & 4,04 & $4,26^{\mathrm{B}}$ & $\hat{y}=4,855268-0,014282 * * N ; R^{2}=0,73$ \\
\hline $80 \%$ de ECA & 4,33 & 4,54 & 5,16 & 4,91 & $4,73^{\mathrm{A}}$ & Sem ajuste \\
\hline
\end{tabular}

* Médias seguidas por letras distintas diferem entre si, pelo teste de Tukey a 5\% de probabilidade. ** Significativo a $1 \%$ de probabilidade. ECA = Evaporação do Tanque Classe A.

Fonte: Elaboração dos autores.

Dentro da lâmina de $50 \%$ de ECA houve resposta linear negativa do Número de Folhas Vivas por perfilho às doses de $\mathrm{N}$ aplicadas (Tabela 5), evidenciando que, mesmo em dosagens elevadas de nitrogênio, a menor disponibilidade hídrica no solo não permitiu maior absorção deste nutriente pelas plantas. Provavelmente, as plantas teriam antecipado o processo de senescência das folhas, através da translocação de nutrientes para auxiliar na expansão de novas folhas, reduzindo o número de folhas vivas. Por sua vez, Fagundes et al. (2006) revelaram que o Número de Folhas Vivas por perfilho do capim-marandu não foi influenciado $(\mathrm{P}>0,05)$ pela adubação nitrogenada, diferenciando dos resultados observados por Martuscello et al. (2005) onde o Número de Folhas Vivas por perfilho aumentou $(\mathrm{P}<0,05)$ proporcionalmente aos níveis de nitrogênio.

\section{Conclusões}

A redução da lâmina de irrigação de $80 \%$ para $50 \%$ de evaporação do tanque Classe A, proporciona decréscimos nas taxas de alongamento da folha, de aparecimento de folha, comprimento final da folha e no número de folhas vivas por perfilho, enquanto, a taxa de senescência aumenta. Doses crescentes de nitrogênio aumentam as taxas de alongamento da folha, aparecimento de folha, comprimento final da folha e senescência, no entanto, tende a reduzir o número de folhas de folhas vivas por perfilho.

\section{Referências}

ALVES, J. de S.; PIRES, A. J. V.; MATSUMOTO, M. P. de; RIBEIRO, G. S. Características morfológicas e estruturais da Brachiaria decumbens Stapf. submetida a diferentes doses de nitrogênio e volumes de água. Acta Veterinaria Brasilica, Mossoró, v. 2, n. 1, p. 1-10, 2008. 
BARBOSA, R. A.; NASCIMENTO JUNIOR, D. do; EUCLIDES, V. P. B.; REGAZZI, A. J.; FONSECA, D. M. Características morfogênicas e acúmulo de forragem de capim-Tanzânia (Panicum maximum Jacq. cv. Tanzânia) em dois resíduos forrageiros pós-pastejo. Revista Brasileira de Zootecnia, Viçosa, v. 31, n. 2, p. 583-93, 2002.

BARRETO, G. P.; LIRA, M. A.; SANTOS, M. V. F.; DUBEUX JUNIOR, J. C. B. Avaliação de clones de capim-elefante (Pennisetum purpureum Schum.) e de um híbrido com o milheto (Pennisetum glaucum (L.) R. Br.) submetidos a estresse hídrico. 1. Parâmetros morfológicos. Revista da Sociedade Brasileira de Zootecnia, Viçosa, v. 30, n. 1, p. 1-6, 2001.

CHAPMAN, D. F.; LEMAIRE, G. Morphogenetic and structural determinants of plant regrowth after defoliation. In: BAKER, M. J. (Ed.). Grasslands for our world. Wellington: SIR Publishing, 1993. p. 55-64.

COSTA, N. de L.; PAULINO, V. T.; MAGALHÃES, J. A. Produção de forragem, composição química e morfogênese de Panicum maximum cv. vencedor sob diferentes níveis de adubação nitrogenada. Revista Científica de Produção Animal, Teresina, v. 8, n. 1, p. 66-72, 2006.

DIAS FILHO, M. B.; CORSI, M.; CUSATO, S. Respostas morfológicas de Panicum maximum, JACQ. cv. Tobiatã ao estresse hídrico. Pesquisa Agropecuária Brasileira, Brasília, v. 24, n. 7, p. 893-898, 1989.

DURU, M.; DUCROCQ, H. Growth and senescence of the successive grass leaves on a tiller ontogenic development and effect of temperature. Annals of Botany, London, v. 85, n. 5, p. 635-643, 2000a.

Growth and senescence of the successive leaves on a Cocksfoot tiller. Effect of nitrogen and cutting regime. Annals of Botany, London, v. 85, n. 5, p. 645653, 2000b.

FAGUNDES, J. L.; FONSECA, D. M.; MISTURA, C.; MORAIS, R. V. de; VITOR, C. M. T.; GOMIDE, J. A.; NASCIMENTO JUNIOR, D. do; CASAGRANDE, D. R.; COSTA, L. T. da. Características morfogênicas e estruturais do capim-braquiaria em pastagem adubada com nitrogênio avaliadas nas quatro estações do ano. Revista Brasileira de Zootecnia, Viçosa, v. 35, n. 1, p. 21-29, 2006.

GARCEZ NETO, A. F.; NASCIMENTO JUNIOR, D. do; REGAZZI, A. J.; FONSECA, D. M. da; MOSQUIM, P. R.; GOBBI, K. F. Respostas morfogênicas e estruturais de Panicum maximum cv. Mombaça sob diferentes níveis de adubação nitrogenada e alturas de corte. Revista Brasileira de Zootecnia, Viçosa, v. 31, n. 5, p. 18901900, 2002.
GASTAL, F.; NELSON, C. J. Nitrogen use within the growing leaf blade of tall fescue. Plant Physiology, Rockville, v. 105, n. 1, p. 191-197, 1994.

LUDLOW, M. M.; NG, T. T. Leaf elongation rate in Panicum maximum var. Trichoglume following removal of water stress. Australian Journal of Plant Physiology, Collingwood, v. 4, n. 2, p. 263-272, 1977.

MARTUSCELLO, J. A.; FONSECA, D. M. da; NASCIMENTO JUNIOR, D. do; SANTOS, P. M.; RIBEIRO JUNIOR, J. I.; CUNHA, D. de N. F. da ; MOREIRA, L. de M. Características morfogênicas e estruturais do capim-xaraés submetido à adubação nitrogenada e desfolhação. Revista da Sociedade Brasileira de Zootecnia, Viçosa, v. 34, n. 5, p. 1475-1482, 2005.

MELO, F. B.; CAVALCANTE, A. C.; ANDRADE JÚNIOR, A. S.; BASTOS, E. A. Levantamento detalhado dos solos da área da Embrapa Meio-Norte/UEP de Parnaíba. Embrapa Meio-Norte, 2004. 26 p. (Embrapa Meio Norte. Documentos, 89).

MESQUiTA, E. E.; NERES, M. A. Morfogênese e composição bromatológica de cultivares de Panicum maximum em função da adubação nitrogenada. Revista Brasileira de Saúde Produção Animal, Salvador, v. 9, n. 2, p. 201-209, 2008.

MOCHEL FILHO, W. de J. E. Fluxo de biomassa, produção de forragem e composição quimicobromatológica do capim-Mombaça sob adubação e irrigação. 2009. Dissertação (Mestrado em Zootecnia) Universidade Federal do Ceará, Fortaleza.

NABINGER, C.; PONTES, L. S. Morfogênese de plantas forrageiras e estrutura do pasto. In: REUNIÃO ANUAL DA SOCIEDADE BRASILEIRA DE ZOOTECNIA, Piracicaba, 2001. Anais... Piracicaba: FEALQ, 2001. p. 755-770.

PARSONS, A. J.; PENNING, P. D. The effect of the duration of regrowth on photosynthesis, leaf death and the average rate of growth in a rotationally grazed sward. Grass and Forage Science, Oxford, v. 43, n. 1, p. 15-27, 1988.

PINTO, J. C.; GOMIDE, J. A.; MAESTRI, M. Crescimento de folhas de gramíneas forrageiras tropicais, cultivadas em vasos, com duas doses de nitrogênio. Revista Brasileira de Zootecnia, Viçosa, v. 23, n. 3, p. 327-332, 1994.

POMPEU, R. C. F. F.; CÂNDIDO, M. J. D. ; LOPES, M. N.; G.; F. H. T. ; LACERDA, C. F.; AQUINO, B. F.; MAGALHÃES, J. A. Características morfofisiológicas do capim-aruana sob diferentes doses de nitrogênio. Revista Brasileira de Saúde Produção Animal, Salvador, v. 11, n. 4, p. 1187-1210, 2010. 
RODRIGUES, T. J. D.; RODRIGUES, L. R. A.; REIS, R. A. Adaptação de plantas forrageiras a condições adversas. In: SIMPÓSIO SOBRE ECOSSISTEMAS DE PASTAGENS, 2., 1993, Jaboticabal. Anais... Jaboticabal: FUNEP-UNESP, 1993. p. 17-61.

SANTOS, R.; CARLESSO, R. Déficit hídrico e os processos morfológicos e fisiológicos das plantas. Revista Brasileira de Engenharia Agrícola e Ambiental, Campina Grande, v. 2, n. 3, p. 287-294, 1998.

SKINNER, R. H.; NELSON, C. J. Elongation of the grass leaf and its relationship to the phyllochron. Crop Science, Oxford, v. 35, n. 1, p. 4-10, 1995.
WILSON, R. J.; MANNETJE, L. Senescence, digestibility and carbohydrate content of Buffel grass and Green Panic leaves in swards. Australian Journal of Agriculture Research, East Melbourne, v. 29, n. 3, p. 503-516, 1978.

WRIGHT, G. C.; SMITH, R. G.; McWILLIAM, J. R. Differences between two grain sorghum genotypes in adaptation to drought stress. I. Crop growth rate and yield response. Australian Journal of Agricultural Research, East Melbourne, v. 34, n. 6, p. 615-626, 1983.

ZANINE, A. de M.; SANTOS, E. M.; FERREIRA, D. de J. Senescência e acumulo liquido de forragem. Revista Científica Rural, Bagé, v. 12, n. 2, p. 113-125, 2007. 
